\title{
Associations between the Use of Antidepressants and Other Medications
}

\author{
Ray M. Merrill ${ }^{*}$, Arielle A. Sloan \\ Brigham Young University, Provo, Utah \\ Email: "Ray_Merrill@byu.edu
}

Received December 20 ${ }^{\text {th }}$, 2013; revised January 27 $7^{\text {th }}, 2014$; accepted February $5^{\text {th }}, 2014$

\begin{abstract}
Copyright $@ 2014$ Ray M. Merrill, Arielle A. Sloan. This is an open access article distributed under the Creative Commons Attribution License, which permits unrestricted use, distribution, and reproduction in any medium, provided the original work is properly cited. In accordance of the Creative Commons Attribution License all Copyrights (C) 2014 are reserved for SCIRP and the owner of the intellectual property Ray M. Merrill, Arielle A. Sloan. All Copyright (C) 2014 are guarded by law and by SCIRP as a guardian.
\end{abstract}

\begin{abstract}
Purpose: The purpose of this study was to use a pharmacy claims database to identify associations between and the timing of antidepressant and other medication use by age and sex. Material/Methods: A retrospective cohort study was conducted of the 70,519 members of the Deseret Mutual Benefit Administrators (DMBA) insurance company who were continuously covered from the years 2001-2011. Results: During $2009-2011,13.3 \%$ of males and $21.6 \%$ of females had at least one pharmacy claim for antidepressants. Those prescribed one of 25 different drug classifications were more likely than the general population to have used antidepressants the previous year. For all of the drug classifications, the use of antidepressants was significantly more common the same year and the year after the drug was first prescribed. The positive association between antidepressant use and other selected drug classifications generally depended on age rather than sex, with the positive association more pronounced in the youngest age group. Conclusion: The positive association between antidepressant use and other selected drug classifications suggests that depression may both lead to and result from many chronic diseases. This association is the strongest among younger individuals, so this age group proves a valuable target for public health interventions.
\end{abstract}

Keywords: Depression; LDS; Antidepressant; Epidemiology

\section{Introduction}

Depression is a serious medical issue characterized by a variety of debilitating symptoms, such as persistent sadness and anxiety, chronic fatigue, feelings of worthlessness, disturbances in cognitive functioning, and thoughts and attempts of suicide (The American Psychiatric Association, 2000). While the World Health Organization projects that depression will become the leading world cause of disability-adjusted life years (DALY) by 2030, the prevalence of this condition varies across the globe, from 3\% in Japan to 9\% in the United States (Lépine \& Briley, 2011). Even within the United States, the prevalence of depression ranges from $5 \%-7 \%$ in some northern states to $10 \%-15 \%$ in parts of the Deep South (Centers for Disease Control and Prevention, 2012). Clearly, socio-cultural differences influence the prevalence of depression, and understanding what these factors are can offer clues about how to reduce disease burden.

One such influence on the prevalence and severity of depression is the presence of other mental illnesses and chronic diseases (Janszky, Ahlbom, Hallqvist, \& Ahnve, 2007; Clarke \& Currie, 2009; Frasure-Smith \& Lespeance, 2006; Katon, Lin, \& Kroenke, 2007; Holden, Bradfoed, Hall, \& Belton, 2013). Research has shown, for example, that depression increases the risk of cardiovascular disease, diabetes, and pulmonary disease (Janszky, Ahlbom, Hallqvist, \& Ahnve, 2007; Clarke \& Currie,

\footnotetext{
*Corresponding author.
}

2009; Frasure-Smith \& Lesperance, 2006; Katon, Lin, \& Kroenke, 2007; Strine et al., 2008; US Department of Health and Human Services, 2013), while chronic disease, conversely, can also increase the risk of depression (Frasure-Smith \& Lesperance, 2006; Katon et al., 2007; Strine et al., 2008; US Department of Health and Human Services, 2013; Pratt, Brody, \& Gu, 2011; National Center for Health Statistics, 2011). However, the strength of that association remains unclear for many chronic diseases and public health funding to tackle the problem is limited. Teasing out which chronic diseases most heavily influence the incidence of depression will allow us to develop more targeted public health interventions.

It is possible to obtain a fairly complete picture of the level of depression and other coexisting chronic conditions using pharmaceutical claims data. However, these data are more useful because they enable us to look at the timing of medication prescription. This information can tell us something about whether depression preceded, was concurrent with, or followed the other chronic condition. It can also inform us about the subpopulations in which the associations between antidepressant use and other medication use are the strongest.

We chose a specific population as the focus for this study because it is connected to a comprehensive prescription claims database. This population consists of the insured family members of employees of the Church of Jesus Christ of Latter-day Saints (LDS), most of whom reside in the state of Utah, where 
the state's population is about 70\% LDS (Walch, 2006). While the prevalence of depression in Utah is close to the national average (Centers for Disease Control and Prevention, 2012), it has a comparatively high rate of antidepressant drug prescriptions (Walch, 2006). This contradiction is not explained satisfactorily by antidepressant abuse because antidepressants do not have the potent addictive properties of other kinds of medication (Royal College of Psychiatrists, 2012). Some of the comparatively high use of antidepressants may be because LDS have a health code that discourages consumption of alcohol, tobacco, and illegal drugs, which are commonly used substances to self-medicate for depression. It may also be that people in Utah are more likely to seek medical treatment for depression than other populations with similar problems. Such a situation makes this population ideal for exploring links between depression and other conditions through pharmaceutical claims data.

This study will contribute to the current depression literature by assessing the association between and timing of antidepressant and other medication use from the DMBA insurance claims database. The timing of antidepressant use relative to other medications and the effect of age and sex on the relationships will also be considered in order to understand drug and disease trends.

\section{Methods}

\section{Study Population}

A retrospective cohort study was conducted with data from the Deseret Mutual Benefit Administrators (DMBA). Deseret Mutual Benefit Administrators is a health insurance company for employees of the Church of Jesus Christ of Latter-day Saints. The company began in 1970 to provide health insurance and retirement income to Church employees and their families. There are about 80,000 individuals covered by the DMBA each year. Employee turnover is estimated to be below 5\% per year (Merrill, Lyon, Baker, \& Bren, 2009). Most change in DMBA enrollment consists of young adults who lose eligibility for coverage under their parents' health insurance plan. Church membership is required for DMBA enrollment in most settings, except for the Church's Deseret Management Company and a few selected other companies. These companies involve about $10 \%-12 \%$ of all enrollees. We do not know the proportion of these enrollees who are Latter-day Saints.

During 2001 through 2011, there were 152,714 persons ( $33 \%$ contract holders, $24 \%$ spouses, and $43 \%$ dependent children) in the DMBA database, with 884,949 person-years. The majority of contract holders (70\%) lived in Utah, where approximately $62.2 \%$ of the population is LDS (Canham, 2012). Approximately $45.6 \%$ of contract holders were employed in the Latter-day Saint Church Education System, principally as teachers; 21.1\% of enrollees were maintenance and custodial workers; and the remaining 33.3\% work in other capacities for the Church. Low prevalence of tobacco smoking, alcohol consumption, and illicit drug use characterizes enrollees in DMBA because such substances are proscribed by the Latter-day Saint Church (Merrill, Lindsay, \& Lyon, 1999).

Mean age increased from $34.7(S D=23.3)$ in 2001 to 36.6 $(S D=24.4)$ in 2011 . The percentage of males was slightly lower than females (49.1\% vs. $50.9 \%$ ). At age 65 , many move to Medicare but purchase supplemental insurance through DMBA. The supplemental insurance should capture all new claims for these individuals.

The database was de-identified according to Health Insurance Portability and Accountability Act (HIPAA) guidelines and was exempt from the need for informed consent by the Institutional Review Board at the University of Utah. The current study was approved and classified as a low-risk study by the Institutional Review Board.

This study used antidepressants as a proxy for depression and used other medications as a proxy for other chronic diseases.

\section{Statistical Techniques}

Counts, percentages, and incidence rates were used to describe the data. Each person's contribution of observable time was calculated based on year end enrollment data and an overall person-time denominator was obtained. Rate ratios were used to measure the association between medications and antidepressant use. Ninety-five percent confidence intervals were calculated for the rates and rate ratios. Rate ratios were considered significant if the confidence interval did not overlap 1 . The Breslow-Day test was used to assess homogeneity among stratified rate ratios. Statistical significance was based on the twosided hypothesis and a P value of 0.05 or less. Analyses were performed using SAS 9.3 (SAS Institute Inc., Cary, NC, 20022010).

\section{Results}

Incidence rates of persons prescribed antidepressant drugs by year are shown in Table 1 . The rates were significantly greater in 2009-2011 compared with earlier years. The ratio of femaleto-male incidence rates of antidepressant drug use ranged from 1.62 to 1.68 over the study period.

During 2009-2011, $13.3 \%$ of males and $21.6 \%$ of females had at least one pharmacy claim for antidepressants. The percentage of persons prescribed antidepressant drugs increased with age for both males and females (Figure 1). There was no difference in antidepressant prescription rates between males and females in the age group 0 - 17, but the rates were significantly greater for females in all other age groups, particularly in the age range $25-44$.

From the list of prominent medication classifications shown in Table 2, the mean number of non-antidepressant prescription drug claims during 2009-2011 is presented by age and sex in Figure 2. Mean number of prescriptions increased with age and, except for the youngest age group, was significantly greater among females. The higher use of non-antidepressant drugs among females is most pronounced in the ages 18 - 44 years.

The percentage of males and females prescribed antidepressants was positively associated with the frequency of prescriptions for other medications (Figure 3). In the age range 25 - 44 and older, a higher percentage of women compared with men was prescribed antidepressants, regardless of the frequency of other prescribed medications. The higher percentage tended to increase with age group.

The percentage of those receiving antidepressants is shown according to whether other selected medications were prescribed for the first time in 2010 (Table 2). For example, 324 people were prescribed amphetamines for the first time in 2010 . The percent prescribed antidepressant medication was $34.0 \%$ in 2009, $47.2 \%$ in 2010 , and $43.2 \%$ in 2011 . The incidence rate of antidepressant use in 2009 was 4.03 times greater among indi- 
Table 1.

Incidence rate of persons prescribed antidepressant drugs, 2001-2011.

\begin{tabular}{|c|c|c|c|c|c|c|}
\hline Year & Person-years & Persons Prescribed Antidepressants & Incidence Rate (\%) & $95 \%$ CI & Female to Male Ratio ${ }^{*}$ & $95 \% \mathrm{CI}^{*}$ \\
\hline 2001 & 78,220 & 8504 & 10.9 & $10.7-11.1$ & 1.67 & $1.60-1.74$ \\
\hline 2002 & 78,964 & 8896 & 11.3 & $11.0-11.5$ & 1.62 & $1.56-1.69$ \\
\hline 2003 & 79,662 & 8963 & 11.3 & $11.0-11.5$ & 1.63 & $1.56-1.70$ \\
\hline 2004 & 80,023 & 9227 & 11.5 & $11.3-11.8$ & 1.62 & $1.56-1.69$ \\
\hline 2005 & 78,254 & 8782 & 11.2 & $10.8-11.4$ & 1.68 & $1.61-1.75$ \\
\hline 2006 & 77,263 & 8482 & 11.0 & $10.8-11.2$ & 1.67 & $1.61-1.75$ \\
\hline 2007 & 80,112 & 8536 & 10.7 & $10.4-10.9$ & 1.68 & $1.61-1.75$ \\
\hline 2008 & 81,678 & 8632 & 10.6 & $10.4-10.8$ & 1.66 & $1.59-1.73$ \\
\hline 2009 & 82,067 & 9771 & 11.9 & $11.7-12.1$ & 1.68 & $1.62-1.75$ \\
\hline 2010 & 82,299 & 9999 & 12.1 & $11.9-12.4$ & 1.66 & $1.59-1.72$ \\
\hline
\end{tabular}

Note: Data source: DMBA. *Adjusted for age.

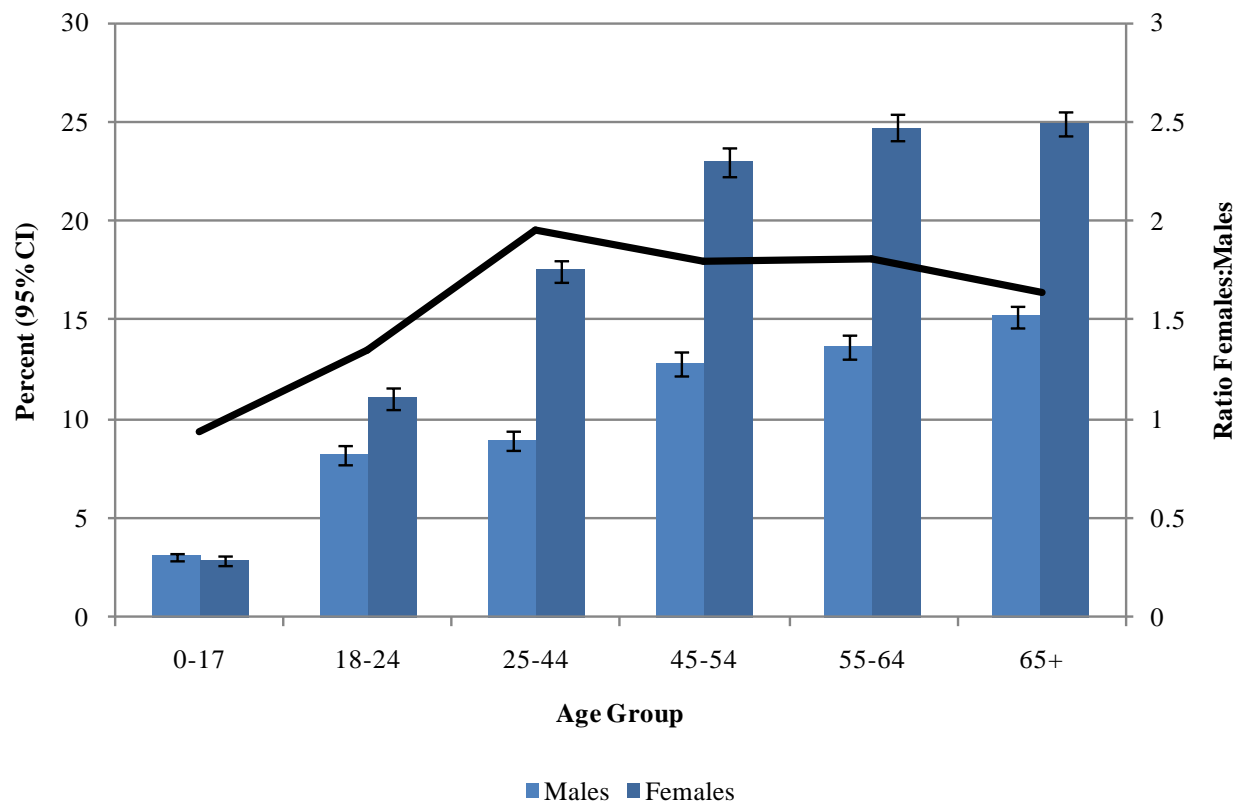

Figure 1.

Percentage of persons prescribed antidepressants by age and sex, 2009-2011.

viduals prescribed amphetamine in 2010; the incidence rate of antidepressant use in 2010 was 5.17 times greater among individuals prescribed amphetamine in 2010; and the incidence rate of antidepressant use in 2011 was 4.43 times greater among individuals prescribed amphetamine in 2010. Thus, higher levels of antidepressant use preceded, occurred during, and followed amphetamine use. The higher levels tended to be greatest in 2010, followed by 2011 and 2009. A similar pattern is seen across the different types of medication.

The Breslow-Day test for homogeneity indicated that the relationship between those prescribed antidepressants according to other selected medication use was generally dependent on age, but not on sex. Table 3 shows the rate ratios in Column 2 of Table 2 by age group. For many of the medications, the positive association with antidepressant use was more pronounced in the youngest age group; that is, the chronic conditions these medications were meant to treat tend to be more strongly associated with depression in younger ages.

\section{Discussion}

Antidepressant use significantly increased over the study period. This finding could be explained, at least in part, by several factors, such as the increasing popularity of the SSRI and SNRI antidepressants introduced to the market in the 1980s and 90s (Kalmar et al., 2008; Hall et al., 2003; Lieberman, 2003; Spence, 2013). The rise in prescription antidepressant use may also be due in part to widespread over-diagnosis or misdiagnosis (Mojtabi, 2013), although this hypothesis has been controversial. Others point to the increased use of antidepressants to treat other conditions, such as anxiety, eating or sleeping disorders, or obsessive compulsive disorders (Pratt et al., 2011). 
Table 2.

Incidence of antidepressant drug use according to first time prescription of other medications in 2010.

\begin{tabular}{|c|c|c|c|c|c|c|c|c|c|c|}
\hline \multirow[t]{2}{*}{ Medication } & \multirow{2}{*}{$\begin{array}{c}\text { 1st time prescription in } 2010 \\
\text { No. }\end{array}$} & \multirow{2}{*}{$\begin{array}{c}2009 \\
\%\end{array}$} & \multirow{2}{*}{$\begin{array}{c}2010 \\
\%\end{array}$} & \multirow{2}{*}{$\begin{array}{c}2011 \\
\%\end{array}$} & \multicolumn{2}{|c|}{2009} & \multicolumn{2}{|c|}{2010} & \multicolumn{2}{|c|}{2011} \\
\hline & & & & & Rate Ratio ${ }^{*}$ & $95 \% \mathrm{CI}^{*}$ & Rate Ratio $^{*}$ & $95 \% \mathrm{CI}^{*}$ & Rate Ratio ${ }^{*}$ & $95 \% \mathrm{CI}^{*}$ \\
\hline Amphetamine & 324 & 34.0 & 47.2 & 43.2 & 4.03 & $3.49-4.65$ & 5.17 & $4.65-5.75$ & 4.43 & 3.93-4.99 \\
\hline CNS Stimulants & 212 & 25.9 & 37.3 & 36.3 & 3.74 & $3.05-4.57$ & 4.92 & $4.21-5.75$ & 4.47 & $3.79-5.28$ \\
\hline Anticonvulsants & 1070 & 38.7 & 53.4 & 48.1 & 2.42 & $2.24-2.61$ & 3.20 & $3.01-3.40$ & 2.76 & $2.59-2.94$ \\
\hline Ataractics-Tranquilizers & 1708 & 32.0 & 45.2 & 42.7 & 2.04 & $1.90-2.19$ & 2.78 & $2.63-2.93$ & 2.52 & $2.38-2.67$ \\
\hline Antiparkinsons & 255 & 39.6 & 45.5 & 42.8 & 2.29 & $1.97-2.65$ & 2.49 & $2.18-2.85$ & 2.26 & $1.96-2.60$ \\
\hline Non-Narcotic Analgesics & 553 & 29.8 & 40.1 & 37.1 & 1.97 & $1.73-2.23$ & 2.48 & $2.24-2.75$ & 2.21 & $1.98-2.46$ \\
\hline Sedative Non-Barbiturate & 1214 & 29.6 & 41.1 & 38.1 & 1.82 & $1.67-1.99$ & 2.41 & $2.25-2.58$ & 2.14 & $1.99-2.30$ \\
\hline Androgens $^{\dagger}$ & 191 & 22.5 & 30.9 & 29.8 & 1.84 & $1.41-2.41$ & 2.34 & $1.88-2.90$ & 2.13 & $1.71-2.67$ \\
\hline Cholesterol Reducers & 151 & 33.1 & 39.7 & 34.4 & 1.74 & $1.39-2.18$ & 2.00 & $1.65-2.42$ & 1.68 & $1.35-2.09$ \\
\hline Anti-Ulcer Drugs & 2273 & 21.5 & 27.4 & 27.4 & 1.37 & $1.27-1.48$ & 1.67 & $1.56-1.79$ & 1.61 & $1.50-1.72$ \\
\hline Adrenergics & 358 & 19.6 & 21.5 & 19.8 & 1.58 & $1.29-1.92$ & 1.62 & $1.34-1.95$ & 1.42 & $1.17-1.74$ \\
\hline Antihistamines & 2541 & 21.0 & 24.4 & 24.4 & 1.46 & $1.35-1.57$ & 1.60 & $1.49-1.71$ & 1.53 & $1.43-1.64$ \\
\hline Antiparasitics & 918 & 23.4 & 25.9 & 25.8 & 1.51 & $1.35-1.69$ & 1.57 & $1.41-1.75$ & 1.51 & $1.36-1.68$ \\
\hline Fungicides & 2885 & 22.7 & 25.2 & 25.3 & 1.51 & $1.41-1.62$ & 1.57 & $1.48-1.68$ & 1.52 & $1.42-1.62$ \\
\hline Estrogens ${ }^{\ddagger}$ & 629 & 28.3 & 34.7 & 36.9 & 1.29 & $1.14-1.47$ & 1.53 & $1.37-1.70$ & 1.58 & $1.42-1.75$ \\
\hline Bronchial Dilators & 2500 & 17.0 & 19.4 & 19.9 & 1.42 & $1.31-1.55$ & 1.52 & $1.41-1.65$ & 1.49 & $1.38-1.61$ \\
\hline Diabetic Therapy & 737 & 20.4 & 27.3 & 28.2 & 1.20 & $1.04-1.38$ & 1.52 & $1.35-1.71$ & 1.51 & $1.35-1.70$ \\
\hline Cardiovascular & 1366 & 20.2 & 27.2 & 27.1 & 1.17 & $1.05-1.30$ & 1.50 & $1.38-1.64$ & 1.44 & $1.32-1.58$ \\
\hline Diuretics & 1176 & 22.0 & 27.8 & 27.0 & 1.20 & $1.08-1.34$ & 1.45 & $1.32-1.60$ & 1.36 & $1.24-1.50$ \\
\hline Antivirals & 1217 & 20.1 & 23.5 & 23.9 & 1.30 & $1.17-1.46$ & 1.44 & $1.30-1.59$ & 1.41 & $1.27-1.55$ \\
\hline Lipotropics & 1676 & 19.2 & 25.8 & 26.0 & 1.10 & $1.00-1.22$ & 1.42 & $1.31-1.55$ & 1.38 & $1.27-1.50$ \\
\hline Anticoagulants & 906 & 22.7 & 26.5 & 26.7 & 1.26 & $1.11-1.42$ & 1.40 & $1.26-1.56$ & 1.36 & $1.22-1.52$ \\
\hline Hypotensives & 1494 & 17.7 & 24.4 & 25.6 & 1.03 & $0.92-1.15$ & 1.36 & $1.24-1.49$ & 1.38 & $1.26-1.50$ \\
\hline Antineoplastics & 393 & 20.9 & 24.4 & 25.2 & 1.20 & $0.99-1.46$ & 1.34 & $1.12-1.59$ & 1.33 & $1.12-1.58$ \\
\hline Antiarthritics & 4517 & 17.6 & 20.8 & 21.4 & 1.18 & $1.10-1.26$ & 1.33 & $1.25-1.41$ & 1.31 & $1.24-1.39$ \\
\hline Oral contraceptives $^{\ddagger}$ & 694 & 14.6 & 18.4 & 17.3 & 1.12 & $0.93-1.35$ & 1.33 & $1.13-1.56$ & 1.18 & $1.00-1.40$ \\
\hline Progesterone $e^{\ddagger}$ & 323 & 24.2 & 26.0 & 24.2 & 1.30 & $1.07-1.58$ & 1.30 & $1.08-1.57$ & 1.18 & $0.97-1.43$ \\
\hline Narcotic Analgesics & 7745 & 15.7 & 18.1 & 18.7 & 1.14 & $1.08-1.21$ & 1.25 & $1.19-1.32$ & 1.24 & $11.18-1.30$ \\
\hline
\end{tabular}

Note: First time medication use in 2010 means that the person was not prescribed the medication any time in 2009. ${ }^{*}$ Adjusted for age and sex. ${ }^{\dagger}$ Males only. ${ }^{\ddagger}$ Females only.

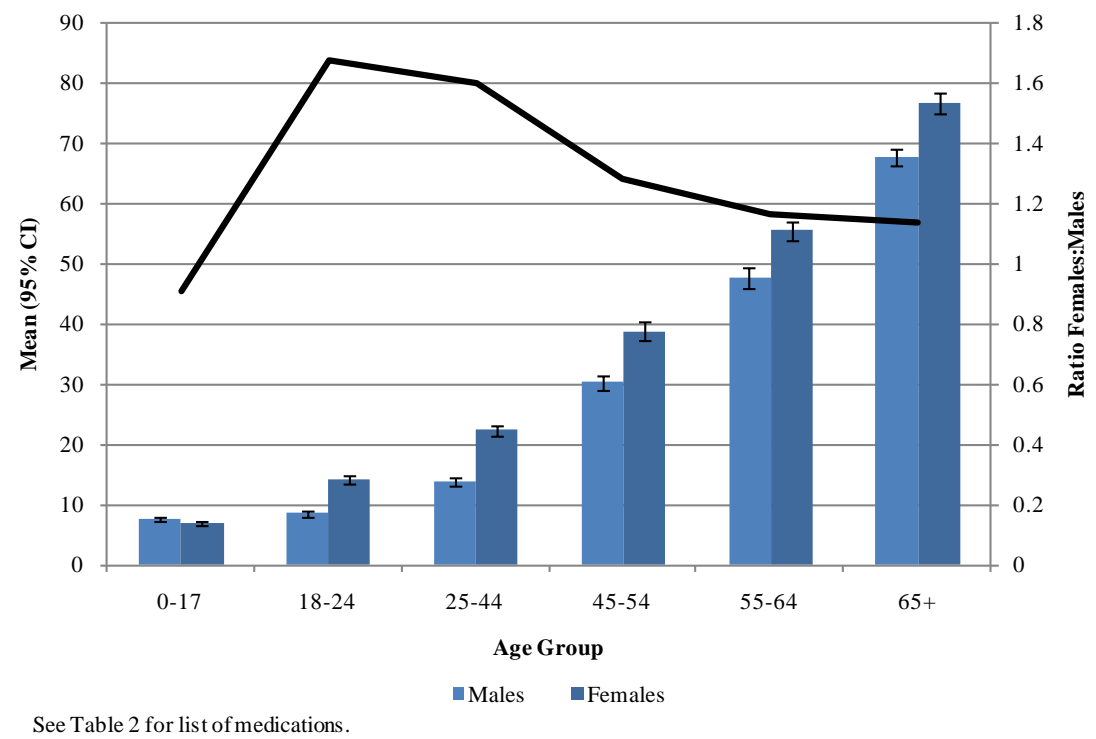

Figure 2.

Mean number of non-antidepressant prescriptions by age and sex, 2009-2011. 


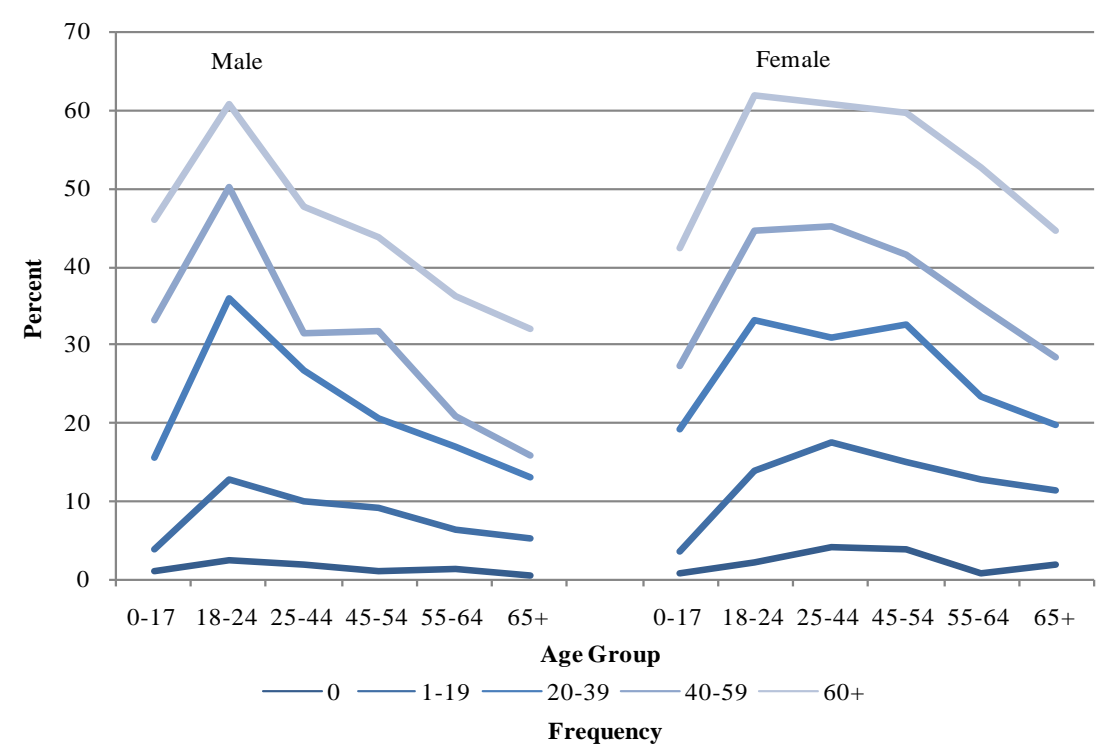

Figure 3.

Percent prescribed antidepressants by age, sex, and frequency of prescribed non-antidepressants, 2009-2011.

Table 3.

Incidence rate ratios of antidepressant use according to other first time medication use in 2010.

\begin{tabular}{|c|c|c|c|c|c|c|}
\hline & $0-17$ & $18-24$ & $25-44$ & $45-54$ & $55-64$ & $65^{+}$ \\
\hline Medication & Rate Ratio $^{*}$ & Rate Ratio $^{*}$ & Rate Ratio* & Rate Ratio $^{*}$ & Rate Ratio $^{*}$ & Rate Ratio* \\
\hline Amphetamine & 13.30 & 4.25 & 4.45 & 3.87 & 3.89 & 2.22 \\
\hline CNS Stimulants & 9.40 & 4.05 & 4.38 & 3.48 & 2.25 & 3.80 \\
\hline Anticonvulsants & 23.88 & 7.62 & 4.19 & 3.39 & 2.68 & 2.15 \\
\hline Ataractics-Tranquilizers & 13.10 & 6.28 & 3.44 & 2.75 & 2.15 & 2.00 \\
\hline Antiparkinsons & 9.90 & 6.05 & 2.14 & 4.15 & 3.05 & 1.61 \\
\hline Non-Narcotic Analgesics & 10.63 & 3.29 & 2.58 & 2.29 & 2.35 & 1.91 \\
\hline Sedative Non-Barbiturate & 7.26 & 4.76 & 3.25 & 2.49 & 2.14 & 1.91 \\
\hline Androgens $^{\dagger}$ & --- & 4.07 & 5.71 & 2.23 & 2.47 & 1.57 \\
\hline Cholesterol Reducers & --- & 6.86 & --- & 1.88 & 1.99 & 1.74 \\
\hline Anti-Ulcer Drugs & 3.65 & 2.92 & 1.57 & 1.77 & 1.63 & 1.47 \\
\hline Adrenergics & 1.56 & 2.30 & 1.82 & 1.55 & 1.80 & 1.14 \\
\hline Antihistamines & 3.03 & 1.97 & 1.43 & 1.63 & 1.53 & 1.49 \\
\hline Antiparasitics & 1.67 & 2.35 & 1.51 & 1.88 & 1.70 & 1.25 \\
\hline Fungicides & 2.36 & 2.18 & 1.45 & 1.67 & 1.55 & 1.46 \\
\hline Estrogens ${ }^{\ddagger}$ & --- & --- & 2.44 & 1.87 & 1.24 & 1.37 \\
\hline Bronchial Dilators & 1.66 & 1.46 & 1.45 & 1.77 & 1.72 & 1.23 \\
\hline Diabetic Therapy & 2.85 & 3.24 & 1.82 & 1.73 & 1.48 & 1.17 \\
\hline Cardiovascular & 15.61 & 2.54 & 2.50 & 1.84 & 1.44 & 1.20 \\
\hline Diuretics & --- & 2.78 & 2.22 & 1.99 & 1.43 & 1.22 \\
\hline Antivirals & 3.71 & 1.15 & 1.50 & 1.43 & 1.27 & 1.46 \\
\hline Lipotropics & 17.47 & 5.68 & 1.82 & 1.56 & 1.50 & 1.21 \\
\hline Anticoagulants & --- & --- & 1.48 & 1.49 & 1.76 & 1.25 \\
\hline Hypotensives & 18.92 & 3.86 & 1.89 & 1.46 & 1.40 & 1.00 \\
\hline Antineoplastics & 3.78 & 3.07 & 1.38 & 1.52 & 1.75 & 0.99 \\
\hline Antiarthritics & 3.79 & 1.47 & 1.26 & 1.45 & 1.35 & 1.11 \\
\hline Oral contraceptives ${ }^{\ddagger}$ & 8.88 & 1.57 & 1.12 & 0.69 & --- & --- \\
\hline Progesterone $e^{\ddagger}$ & 5.82 & 2.34 & 1.11 & 1.58 & 0.89 & 1.41 \\
\hline Narcotic Analgesics & 2.14 & 1.46 & 1.32 & 1.24 & 1.22 & 1.10 \\
\hline
\end{tabular}

Note: All ratios are statistically significant at the 0.05 level except those that are shaded. In addition, first time medication use in 2010 means that the person was not prescribed the medication any time in 2009. - '-Insufficient numbers to compute. ${ }^{*}$ Adjusted for sex. ${ }^{\dagger}$ Males only. ${ }^{\ddagger}$ Females only. 
Antidepressant use was approximately 1.65 times greater in females than in males in our study. This ratio is very close to the 1.66 value nationally, based on the 2011 Behavior Risk Factor Surveillance System (BRFSS) Survey responses to the question: "Has a doctor ever told you that you have a form of depression?” (Behavior Risk Factor Surveillance System, 2011). A number of reasons have been given for higher levels of depression among women than men, including endocrine, psychosocial, and genetic factors (Merikangas, Weissman, \& Pauls, 1985). The finding that antidepressant use was greater in females throughout much of the life span reflects previous research (Kalmar et al., 2008), including 2012 national data on depression prevalence (Centers for Disease Control and Prevention, 2012). The greatest contrast in depression between males and females was in the age group 25 - 44, which is likely explained by the fact that a large percentage of women who experience pregnancy have post-partum depression (University of Maryland Medical Center, 2013; Piccinelli \& Wilkinson, 2000).

Although previous research has found that depression becomes less common later in life (Kessler et al., 2010; Centers for Disease Control and Prevention, 2012), the use of antidepressants increased with age in our study, albeit only slightly, from ages 55 - 64 to 65 and older. It may be that antidepressants are increasingly being used to treat other conditions that become more common in older age, although more research is warranted on the subject.

The non-antidepressant medications considered in this study are used to treat an array of health conditions. The mean number of prescribed non-antidepressant medications increased sharply with age, as expected, with the frequency of prescribed drugs more common in females than males, especially in the age range 18 through 44 . In part, this may be because women are more likely than men to suffer from other chronic diseases, including anxiety disorders and neuroticism. However, part of this gap may be due to higher levels of prescription drug abuse among women. Research has shown that women are more likely to use prescription drugs for non medical purposes and are more likely to have exposure to drugs with abuse potential, including narcotic analgesics and minor tranquilizers (SimoniWastila, Ritter, \& Strickler, 2004). It has also been suggested that women have biologic and physiologic differences that make them potentially more susceptible to drug abuse (SimoniWastila et al., 2004).

Antidepressant use was significantly more common in those who went on and developed other chronic diseases, increased during the same year as the chronic disease, and then remained significantly positive in the year following the first prescribed medication for the chronic disease. This result confirms previous research where depression was shown to be a risk factor for several chronic conditions (Lépine \& Briley, 2011; Centers for Disease Control and Prevention, 2012; Janszky et al., 2007; Clarke \& Currie, 2009; Frasure-Smith \& Lesperance, 2006; Katon et al., 2007; Almeida, Alfonso, Hankey, \& Flicker, 2010; Moussavi et al., 2007; Pratt et al., 1996), and chronic disease, conversely, was shown to be a risk factor for depression (Janszky et al., 2007; Clarke \& Currie, 2009; Frasure-Smith \& Lesperance, 2006; Katon et al., 2007; Holden et al., 2013; Strine et al., 2008). A large longitudinal study has shown that depression is associated with future health-compromising behaviors (Walsh, Senn, \& Carey, 2013), which helps explain increased risk for several chronic conditions that are lifestyle- related. Comparatively high antidepressant use in the same year as the first time chronic disease diagnosis is likely explained by the shock of the diagnosis, difficulty in coping, changes in lifestyle, and a sense of fear and hopelessness. Then, the continued, significantly higher levels of antidepressant drugs the year following a first-time chronic disease diagnosis may be due to the debilitating effects of the disease in combination with the potentially addictive properties of antidepressants (Simoni-Wastila et al., 2004).

The strongest association with antidepressant use was with amphetamines, central nervous system stimulants, anticonvulsants (sometimes used to stabilize mood and treat bipolar disorder and borderline personality disorder), and ataractics-tranquilizers. These drugs are commonly used for treating mental health conditions like attention deficit disorder, hyperactivity disorder, and psychoses. The relatively strong association between these drugs and antidepressants is consistent with a recent study finding that autism, ADHD, bipolar disorder, schizophrenia, and major depression share common genetic risk factors (Serretti \& Fabbri, 2013). In addition, the combination of antidepressant drugs and other forms of medication has the potential for further adverse health outcomes. For example, the antidepressant Zoloft (Sertraline) has 201 known major drug interactions and a moderate drug interaction with alcohol (ethanol). Furthermore, Zoloft has been shown to increase risk for seven diseases (liver disease, mania, altered platelet function, seizure disorders, syndrome of inappropriate antidiuretic hormone secretion, renal dysfunction, and weight loss) (Drugs.com, 2013).

For many of the medications, the chronic conditions they are intended to treat were generally more strongly associated with depression in younger ages. For example, non-narcotic and narcotic analgesics had a much greater positive association with antidepressant use in the youngest age group. Pain associated with a disease can reduce serotonin levels, thereby causing depression. It may be that younger people are more sensitive to low serotonin levels with respect to depression. It may also be that the symptoms of the chronic disease (e.g., limited activity or visible and obvious outcomes making the person feel embarrassed and inadequate) can be more upsetting for younger people; that medications used to treat chronic disease may lead to greater risk for depression among children (e.g., prednisone for treating severe asthma, arthritis, and inflammatory bowel disease, or Phenobarbital or Carbamazepam used to treat epilepsy); that children have a more difficult time coping with treatment regimens that are difficult to follow; and that the sporadic nature of the chronic disease or loss of social contact with people because of the disease may be more difficult for children. Further research along these lines is warranted.

\section{Conclusion}

Increasing use of antidepressants and greater use of these drugs among females are consistent with other research. Although depression has been shown in other studies to increase through young adulthood and then decrease with old age, use of antidepressants continued to increase across age groups in the current study. This may be because antidepressants are increasingly being used to treat other conditions that become more common in older age. The greatest contrast in antidepressant use between males and females was in the age group 25 - 44, most likely explained by post-partum depression. Consistent with previous research, antidepressant use was a risk factor for 
chronic disease and chronic disease was also a risk factor for antidepressant use. The strongest association with antidepressants was seen with amphetamines, central nervous system stimulants, anticonvulsants, and ataractics-tranquilizers, possibly explained by a genetic link among these conditions and by adverse drug-drug interactions. Finally, the link between many medications used to treat chronic disease and antidepressant drug use is often greater in younger age. Some possible explanations for this observation were suggested, but further research is needed to confirm our speculation.

\section{Acknowledgments}

The authors would like to acknowledge their sponsoring institution for the funding that has supported this project.

\section{Conflict of Interest}

The authors declare that there is no conflict of interests regarding the publication of this article.

\section{REFERENCES}

Almeida, O.P., Alfonso, H., Hankey, G.J., \& Flicker, L. (2010). Depression, antidepressant use and mortality in later life: The health in men study. PLOS ONE, 5, 1-9.

http://dx.doi.org/10.1371/journal.pone.0011266

The American Psychiatric Association (2000). Diagnostic and statistical manual of mental disorders (4th ed.). The American Psychiatric Association, Washington DC.

Behavior Risk Factor Surveillance System (2011). Prevalence and trends data. Nationwide (States and DC).

http://apps.nccd.cdc.gov/brfss/sex.asp?cat=CH\&yr=2011\&qkey=844 1 sstate $=\mathrm{UB}$

Canham, M. (2012). Census: Share of Utah’s mormon residents holds steady. Salt Lake Tribune.

http://www.sltrib.com/sltrib/home3/53909710-200/population-lds-co unty-utah.html.csp

Centers for Disease Control and Prevention (2012). QuickStats: Prevalence of current depression among persons aged $\geq 12$ years, by age group and sex-United States, National Health and Nutrition Examination Survey, 2007-2010.

http://www.cdc.gov/mmwr/preview/mmwrhtml/mm6051a7.htm

Centers for Disease Control and Prevention (Internet) (2012). An estimated 1 in 10 US adults report depression. http://www.cdc.gov/features/dsdepression/

Clarke, D. M., \& Currie, K. C. (2009). Depression, anxiety and their relationship with chronic diseases: A review of the epidemiology, risk and treatment evidence. Medical Journal of Australia, 190, 54-60.

Drugs.com (2013). Zoloft (sertraline) drug interactions. http://www.drugs.com/drug-interactions/sertraline,zoloft.html

Frasure-Smith, N., \& Lesperance, F. (2006). Recent evidence linking coronary heart disease and depression. Canadian Journal of Psychiatry, 51, 730-737.

Hall, W. D., Mant, A., Mitchell, P. B., Rendle, V. A, Hickie, I. B., \& McManus, P. (2003). Association between antidepressant prescribing and suicide in Australia, 1991-2000: Trend analysis. British Medical Journal, 326, 1008. http://dx.doi.org/10.1136/bmj.326.7397.1008

Holden, K. B., Bradford, L. D., Hall, S. P., \& Belton, A. S. (2013). Prevalence and correlates of depressive symptoms and resiliency among African American women in a community-based primary health care center. Journal of Health Care for the Poor and Underserved, 24, 79-93.

Janszky, I., Ahlbom, A., Hallqvist, J., \& Ahnve, S. (2007). Hospitalization for depression is associated with an increased risk for myocardial infarction not explained by lifestyle, lipids, coagulation, and inflammation: The SHEEP study. Biological Psychiatry, 62, 25-32. http://dx.doi.org/10.1016/j.biopsych.2006.08.039
Kalmar, S., Szanto, K., Rihmer, Z., Mazumdar, S., Harrison, K., \& Mann, J. J. (2008). Antidepressant prescription and suicide rates: Effect of age and gender. Suicide and Life-Threatening Behavior, 38, 363-374. http://dx.doi.org/10.1521/suli.2008.38.4.363

Katon, K., Lin, E. H., \& Kroenke, K. (2007). The association of depression and anxiety with medical symptom burden in patients with chronic medical illness. General Hospital Psychiatry, 29, 147-155. http://dx.doi.org/10.1016/j.genhosppsych.2006.11.005

Kessler, R. C., Birnbaum, H., Bromet, E., Hwang, I., Sampson, N., \& Shahly, V. (2010). Age differences in major depression: Results from the national comorbidity surveys replication (NCS-R). Psychological Medicine, 40, 225-237.

http://dx.doi.org/10.1017/S0033291709990213

Lépine, J., \& Briley, M. (2011). The increasing burden of depression. Journal of Neuropsychiatric Disease and Treatment, 7, 3-7.

Lieberman, J. A. III. (2003). History of the use of antidepressants in primary care. The Primary Care Companion-Journal of Clinical Psychiatry, 5, 6-10.

Merikangas, K. R., Weissman, M. M., \& Pauls, D. L. (1985). Genetic factors in the sex ratio of major depression. Psychological Medicine, 15, 63-69. http://dx.doi.org/10.1017/S0033291700020936

Merrill, R. M., Lindsay, G. B., \& Lyon, J. L. (1999). Tobacco-related cancers in Utah compared to the United States: Quantifying the benefits of the Word of Wisdom. BYU Studies, 38, 91-105.

Merrill, R. M., Lyon, J. L., Baker, R. K., \& Gren, L. H. (2009). Attention deficit hyperactivity disorder and increased risk of injury. Advances in Medical Sciences, 54, 20-26. http://dx.doi.org/10.2478/v10039-009-0022-7

Mojtabi, R. (2013). Clinician-identified depression in community settings: Concordance with structured-interview diagnoses. Psychother Psychosom, 82, 161-169. http://dx.doi.org/10.1159/000345968

Moussavi, S., Chatterji, S., Verdes, E., Tandon, A., Patel, V., \& Ustun, B. (2007). Depression, chronic diseases, and decrements in health: Results from the World Health Surveys. Lancet, 370, 851-858. http://dx.doi.org/10.1016/S0140-6736(07)61415-9

National Center for Health Statistics (2011). Health, United States, 2010: With special feature on death and dying. http://www.cdc.gov/nchs/data/hus/hus10.pdf

Piccinelli, M., \& Wilkinson, G. (2000). Gender differences in depression. Critical review. British Journal of Psychiatry, 177, 486-492. http://dx.doi.org/10.1192/bjp.177.6.486

Pratt, L. A., Brody, D. J., \& Gu, Q. (2011). Antidepressant use in persons aged 12 and over: United States, 2005-2008. NCHS Data Brief, 76, 1-8. http://www.cdc.gov/nchs/data/databriefs/db76.pdf

Pratt, L. A., Ford, D. E., Crum, R. M., Armenian, H. K., Gallo, J. J., \& Eaton, W. W. (1996). Depression, psychotropic medication, and risk of myocardial infarction. Prospective data from the Baltimore ECA Follow-up. Circulation, 94, 3123-3129. http://dx.doi.org/10.1161/01.CIR.94.12.3123

Royal College of Psychiatrists (2012). Antidepressants. http://www.rcpsych.ac.uk/healthadvice/treatmentswellbeing/antidepr essants.aspx

Serretti, A., \& Fabbri, C. (2013). Shared genetics among major psychiatric disorders. Lancet, 381, 1339-1341. http://dx.doi.org/10.1016/S0140-6736(13)60223-8

Simoni-Wastila, L., Ritter, G., \& Strickler, G. (2004). Gender and other factors associated with the nonmedical use of abusable prescription drugs. Subst Use Misuse, 39, 1-23. http://dx.doi.org/10.1081/JA-120027764

Spence, D. (2013). Are antidepressants overprescribed? Yes. BMJ, 346, f191. http://dx.doi.org/10.1136/bmj.f191

Strine, T. W., Mokdad, A. H., Balluz, L. S., Gonzalez, O., Crider, R., Berry, J. T., \& Kroenke, K. (2008). Depression and anxiety in the United States: Findings from the 2006 Behavioral Risk Factor Surveillance System. Psychiatric Services, 59, 1383-1390. http://dx.doi.org/10.1176/appi.ps.59.12.1383

University of Maryland Medical Center (2013). Postpartum depression. http://umm.edu/health/medical/pregnancy/your-babys-first-few-week s/postpartum-depression

US Department of Health and Human Services (2013). Mental health and mental disorders, Healthy People 2020. 
http://www.healthypeople.gov/2020/topicsobjectives2020/overview.a spx?topicId=28

Walch, T. (2006). Why high antidepressant use in Utah? Deseret news. http://www.deseretnews.com/article/640196840/Why-high-antidepre ssant-use-in-Utah.html?pg=all
Walsh, J. L., Senn, T. E., \& Carey, M. P. (2013). Longitudinal associations between health behaviors and mental health in low income adults. Translational Behavioral Medicine, 3, 104-113.

http://dx.doi.org/10.1007/s13142-012-0189-5 